\title{
The sustainability and future of energy and environment - a vision to target
}

\author{
Sukanchan Palit ${ }^{1,2}$ \\ ${ }^{1}$ Department of Chemical Engineering, University of Petroleum and Energy Studies, \\ Dehradun - 248007, India \\ ${ }^{2} 43$, Judges Bagan, Post Office - Haridevpur, Kolkata - 700082, India \\ Phone: 0091-8958728093, 0091-3324026947 \\ E-mail address: sukanchan68@gmail.com , sukanchan07@yahoo.com
}

\begin{abstract}
The world of sustainability is changing rapidly. The loopholes of the laws of energy and environmental sustainability are changing and exposed in a vibrant manner. So the ultimate need is to target sustainability in a war-footing. The answers to the wide ranging question of environmental and energy sustainability is far-reaching and ground-breaking to our human society. Environmental and energy sustainability is intricately linked with sustainable development and human survival. The answers to mankind's suffering are intricate, also at the same time visionary and bewildering. The world of unknown in the field of science and technology of renewable energy is giving place to the veritable certainity and knowledge. The plight of human society due to environmental disasters throughout the span of different nations is awesome and immense. The depletion of non-renewable resources has plunged our human society in a disastrous dilemma. Here comes the answer of environmental sustainability and energy sustainability. Environmental restrictions and regulations with the attached unbilical cord of human survival has made our human society to be more rigid and rigorous. This scientific effort highlights the important facets of renewable energy and its impact on human survival in future. The questions of environmental sustainability are varied and unanswered. So the vision of this research effort is to tackle and uncover the hidden aspects of renewable energy and the remedies behind the far-reaching questions of environmental disasters. The endeavour is wide and varied carrying an enormous promise to the answers to human survival in this age of energy and environmental uncertainity.
\end{abstract}

Keywords: environment; energy; renewable; society; mankind; survival; non-renewable

\section{INTRODUCTION}

The world is striving towards major, significant and drastic challenges. Man's as well as scientist's vision is transforming day by day. Global climate changes, environmental catastrophes and natural disasters are forcing the scientific community as well as civil society to move towards more environmental regulations and restrictions.

Sustainability is a common forceful terminology nowadays as the world plunges to one environmental disaster over another. The nuclear disasters at Three Mile Island, Chernobyl 
and Fukushima has casted serious doubts on the scientist's mind. A splendid future of our civilization cannot be foreseen if serious steps are not taken towards environmental sustainability. The question of sustainability especially environmental sustainability has a gloomy yet positive future. A scientist's vision is wide, unparalleled and visionary. The answers to the question of survival on earth is mandatory and far-reaching. The treatise will deal with environmental sustainability particularly global warming and consequential climate change $[1,3,4]$.

Global warming pose the greatest threat and challenge for the survival of the humanity and other life forms in the good earth. There is a universal recognition, acknowledgement and unanimity now among the climate scientists and ecologists at large that the earth's climate is changing more rapidly in recent years than in the past. Largely, among other matters, this is due to phenomenal and massive anthropogenic interferences resultant from ambitious planned growth of energy-intensive industrialization aimed at high GDP in a fiercely hypercompetitive world. Partially, this is attributable to dramatic changes in life-styles, particularly in the developed economies of the world. Climate change is a progressive physical phenomenon of nature and the characteristics, complexity and magnitude of such changes are highly dependent on the rate of carbon intensities in the industrial processes and practices and such changes may be limited to a specific region, or may even move border-less across the globe.

\section{CHALLENGES TO THE MANKIND AND THE GLOBAL CONCERN}

Challenges to the human survival are wide and varied. In today's world the question of sustainability has put the civil society in two minds. But the urgency and vision has urged the world order to gear up towards an endeavour of war-footing. Clear definition of sustainability shows that it should reach the common mass on a grassroot level. Man's concern is clear and well defined. Energy and environmental sustainability needs to be in the forefront of the agenda of every government throughout the world.

Different forces (both biotic and abiotic) that can shape climate change include such processes as variations in solar radiation, deviations in the Earth's orbit, mountain-building, tectonic movement, continental drift, and changes in greenhouse gas(GHG) concentrations.

The question of environmental sustainability is inextricably linked with these causes. Overcoming such forces are the imminent challenges of our mankind. There could be yet a variety of climate change related impacts or feedbacks that can either amplify or retard the initial forcing. Some parts of the climate system, such as the oceans and ice caps, rivers, biosphere reserve forests, lakes etc. may respond rather slowly but permanently in reaction to climate forcing; while others may not.

Therefore, the climate system can take centuries or even longer to fully respond to new external forcing. Documented evidencies shown by World Meteorological Organization (WMO), IPCC, UNFCCC and others clearly point towards various adverse impacts of the climate change at alarming rates in the forms of melting glaciers, outbreak of diseases, loss of biodiversity, erratic and scanty rainfalls causing drought and acute shortage of irrigation and drinking water and repeated crop failures in a vast stretch of landscapes of the planet $[2,4]$.

The major effect is of causing enormous asymmetric economic growth in the developed world in one hand and negative socio-economic impacts and implicit adverse consequences in 
the developed economy on the other-including demographic migration. Thus human society has an inextricable link to the adverse climate change. The understanding of the natural dynamics of the Earth system has advanced greatly through extensive research initiatives in recent years and provides a sound foundation for evaluating the effects; inclusive of the various consequences and effects of human-driven changes for effective monitoring and mitigation.

The global effort to address climate change will require a fundamental transformation of our economies and the ways we use energy. The current phase of negotiations under the UN Framework Convention on Climate Change (UNFCC) is set to lay the foundation and groundwork for the necessary policy reform and will require cooperative efforts by individual countries, the business sector and civil society. Then the question arises of innovation- both with regard to the technology development and transfer in the future and regulatory frameworks used to usher and invite them at the scale needed-will be the key to success. There ought to be an enhanced role for the carbon market, with strong improvement of the CDM and the creation of new sectoral mechanism built-in under the Kyoto Protocol.

The ushering in of Kyoto Protocol has given an impetus to the Copenhagen convention. Man's concern is towards a visionary future as regards climate change and global warming. The question of survival of the fittest is also of primary and visionary importance. After Copenhagen declaration, the world will be a better place to live in with all the constraints and hurdles. United Nations and Inter - Governmental panels will surely rise to the occasion in giving the human society better choices in leadership roles and happy survival. The hurdles are immense at the same time visionary but can be overcome with the tremendous will power, grit and determination of human survival. Hope is a word of the past and questions are answered. Man's vision will lead him towards new destiny and the scientific generations will focus towards a new beginning or a new dawn.

Thus comes the need of a global effort or an integrated global endeavour in bringing about changes-changes so effective and visionary. Rio, Kyoto and subsequently Copenhagen will bring in a new world order and human survival will usher in a new perspective - a perspective so unaltruistic and a perspective so versatile and visionary. Man's survival is the primary issue, so the questions of the future are effectively answered with the global human effort.

\section{FUNDAMENTALS OF SUSTAINABLE DEVELOPMENT AND THE QUESTION OF HUMAN SURVIVAL}

People, planet and profit are the main focus and target towards successful sustainable development along with time and space. "Sustainable development" is a frequently used term, but it is open to a variety of interpretations. Although the Brundtland definition (development that meets the needs of the present without comprising the ability of future generations to meet their own needs) provides a good starting point by focusing on both 'needs' and 'limitations', there has been continued controversy over the exact meaning of the term, and this has often been exacerbated by treating the social, economic and environmental elements either in isolation, or in an unbalanced way. 


\section{TRUE SENSE OF SUSTAINABLE DEVELOPMENT}

Through a wide range of cooperating partners and networks, it is possible to work effectively towards a sustainable future. There are a number of conditions which every future development will have to comply with if human society wishes the civilization to survive.

This collection of requirements that are non-negotiable can then reveal which scientific, technological, economic ,political, legal and social innovations human society will have to come up with. There are twelve of these rigid conditions [11]:

a) The causes of climate change must be eliminated in full.

b) When it comes to the degree to which climate change is now unavoidable, solutions will have to be found for the increasing occurrence of floods, droughts and the weather extremes.

c) Deforestation and encroachment on other natural areas must come to a halt.

d) Pollution and other issues must be cut.

e) Definitive solutions must be found for the rising scarcity of certain natural resourcesenergy sources, materials and clean water.

f) The growth of world's population will have to decrease to zero.

g) But because the population is still set to increase by at least a few billion, it is still essential in the upcoming decades that agricultural and industrial production be upped.

h) Poverty in the world will have to be eradicated.

i) War must be obliterated around the world.

j) Living conditions must be improved, which means that healthcare and education must be available to all.

k) Humanity and human dignity must improve within the framework of society.

1) There are many reasons why there is an increasing need for land. The natural environment needs more space, while the growing and increasingly prosperous world population wants land for the purposes of living, working and recreation. There is also a demand for agricultural land [11].

\section{THE QUESTION OF SUSTAINABLE DEVELOPMENT AND DEPLETION OF ENERGY RESOURCES}

Energy and environmental sustainability are so relevant topics of our present day human society. Fossil fuel sources are depleting day by day. Petroleum and coal reserves in developed as well as developing countries are numbered. So the importance of sustainable development. Man's vision as well as the vision of civil society are truncated as well as emboldened with the passage of time. The world of unknown in the field of renewable energy options needs to be immediately reviewed. There should be no question of delay. The world is waiting anxiously for the solutions of energy sustainability and renewable energy in particular.

\section{HUMAN DESTINY, HUMAN SURVIVAL AND MANKIND}

The question of human destiny and human survival are linked inextricably linked by an unbilical cord. The rigours of human advancement has led to unmitigated disaster-an 
environmental catastrophe. Global warming and climate change are man's own creation. But the urge and the question lies ahead- will it be mitigated. The answers are varied, versatile and visionary. It is positive and true to the human endeavour. Copenhagen, Rio or Kyoto are the strong backbones of a new and positive global order. Environmental sustainability, climate change and global warming are inextricably linked. The vision of tomorrow is undaunting and irreversible. A strong effort and a vital endeavour can change our lifetime $[4,10]$.

\section{THE QUESTION OF CLIMATE CHANGE AND GLOBAL WARMING}

Climate change is a continuous physical phenomenon of nature and generally influenced by anthropogenic forces. The way, nature, complexity and magnitude of such change are universally recognized to be governed by the rules of environmental conditions, ecological balance of nature and more importantly by human interferences of various kinds.

Climate change is a change in the statistical distribution of weather over long periods of time that range from decades to millions of years. It can be considered as a change in the average weather or a change in the distribution of weather events around an average. Climate change may be limited to a specific region, or may occur across the globe [4].

The terms global warming and climate change are often used co-tremendously, but the two phenomenon are different. Global warming is the rise in global temperature due to an increase of heat-trapping carbon emissions in the atmosphere. Climate change, on the other hand is a more general term that refers to changes in many climatic factors (eg: temperature and precipitation) around the world. These changes are happening at different rates and in different ways. The world mostly agrees that something needs to be done about global warming and climate change [4].

Man's as well as human society's vision is wide, unparalleled and far-reaching. The question of global environmental imbalance comes into the picture when the serious catastrophe and turmoil of global warming and climate change shakes human vision. The answers are many as the world and the civil society gear up for preventing imminent environmental disasters. Agreements has been always a stumbling block but the vision is groundbreaking.

The first stumbling block however, has been in attempting to get an agreement on an unanimous framework. The difficult questions are answered. In 1988, the Intergovernmental Panel on Climate Change (IPCC) was created by the United Nations Environment Programme (UNEP) and World Meteorological Organization (WMO) to assess the scientific knowledge on global warming. The IPCC concluded in 1990 that there was broad international consensus that climate change was human-induced. That report led the way to an international convention for climate change - namely the United Nations framework Convention on Climate Change (UNFCC), signed by over 150 countries at the Rio Earth Summit in 1992 [4].

The Intergovernmental Panel on Climate Change (IPCC) reported the phenomena for the first time in 1990. IPCC, inter alia, stated that greenhouse gas (GHG) concentrations in the global atmosphere were rising as a result of anthropogenic emissions, principally from fossil fuel burning. This is clearly an international or a 'global problem'. This is yet another new and far-reaching dimension to the problem. While the global dependency on fossil energy for economic growth remains nearly $100 \%$ at this time, IPCC also noted that cuts in GHG emissions in the order of $60-80 \%$ were required immediately if rising atmospheric GHG 
concentrations were to be stabilized at the present raised values. There is another even more difficult dimension in this problem. The IPCC also noted that stabilization of atmospheric GHG concentrations at any value was contingent on cuts of this magnitude in some given time frame. Scientists have found that the four most important variable greenhouse gases, whose atmospheric concentrations can be influenced by human activities, are carbon dioxide $\left(\mathrm{CO}_{2}\right)$, methane $\left(\mathrm{CH}_{4}\right)$, nitrous oxide $\left(\mathrm{N}_{2} \mathrm{O}\right)$, and chlorofluoro carbons (CFC's). Historically , carbondioxide has been the most important, but those other atmospheric trace gases are also radioactively active, in that they can effect Earth's 'heat - budget' and thereby contribute to a greenhouse warming of the lower atmosphere. The Kyoto Protocol on Climate Change also regulates three other trace gases: viz. hydrofluorocarbons (HFC's), perfluorocarbons (PFC's) and sulphur - hexafluoride (SF6), whose limited concentrations in the atmospheric are anticipated to grow over the long run [4].

The Kyoto Protocol introduced the following three flexibility mechanisms to supplement the domestic activities of the developed countries. The three flexibility mechanisms are:

- Clean Development Mechanism (CDM)

- Joint Implementation (JI)

- International Carbon Trading (ICT) [4].

The country-wise, regional and overall experience implementation of these three mechanisms have widely varied; but nonetheless there do seem only a limited number of such demonstration models available which are truly sustainable and replicable to bring in positive changes through planned or engineered mitigation and adaptation efforts [4].

\section{ENVIRONMENTAL AND ENERGY SUSTAINABILITY AND THE FAR-REACHING VISION}

Mankind has an unbilical cord with energy and environment. The question of depletion of energy resources is alarming and imminent. Successive generations in future will rely on the impact and approval of intense scientific research in the field of energy sustainability. The question of depletion of non-renewable energy resources is today a mind boggling issue to human society and mankind. The impact on the human society is daring and challenging [10].

Interest in renewable energy is growing fast and, faced with rising oil and gas prices, rising energy demand and the burning and pressing issue of climate change, is likely to continue far into the future. There is an extensive and wide range of technologies now commercially available: solar photovoltaics, solar thermal, passive solar, wood energy, wind power, geothermal and air-to-air heat pumps, hydro energy systems as well as energy efficiency measures.

The world is undergoing a revolutionary resurgence in the use of renewable energy for generating electricity, heat and cooling. This phenomenon can be seen as a result of diminishing fossil-fuel resources, and, particularly in the last decade, as a logical reaction to the reality of climate change, which stems in large part from the use of coal, oil and gas.

Renewable energy has been used in some forms-especially wood heating, passive solar, wind and hydro- for thousands of years in homes, public spaces, work situations and for 
agricultural processes. Technological development has been rapid since the 1970s providing new opportunities and greater efficiencies for renewable installations $[5,6,8]$.

Many householders, energy managers and decision makers in businesses or public services are turning to renewable energy sources in order to contribute to the mitigation of climate change. Many are also turning towards renewables because it makes economic and social sense. The long awaited answers to energy and environmental sustainability are visionary and imminent $[5,6,8]$.

In terms of the available resources, hydropower is probably the least widely applicable. Very few properties have legitimate access to the right flow of water and gross head (i.e., the vertical difference between a hydro system's intake and the turbine located in a powerhouse).

This is unfortunate in that, given a good hydro-resource, this is probably the preferred renewable technology for generating electricity. Despite having relatively high initial capital investment costs, hydro systems (like streams and rivers) are typically designed to run 24 hours a day, seven days a week, all year round. The human society and mankind cannot depend on wind or solar resources in most locations.

\section{ISSUES OF ENERGY SUSTAINABILITY IN A DEVELOPING COUNTRY LIKE INDIA}

The International Energy Agency has identified the development of renewable energy resources as a key element to mitigate climate change. At the same time it has projected India to be the second largest contributor to the increase in global energy demand to 2035. India hence faces a significant and considerable challenge to ensure its energy security by diversifying its power generation mix. In the wake of creation of a Green Climate Fund in Cancun, there were empirical studies on the effect of the introduction of Electricity Act 2003 and Tariff Policy 2006 as well as feed-in tariffs and minimum quotas on clean electricity sourcing, on the development of grid-connected renewable energy power in nine Indian states over the period 2001-2009. Results suggest that the passing of the Tariff Policy 2006, statelevel policies, quantity based instruments and a greater participation of the private sector have played a key role in promoting the development of installed capacity of renewable energy power in nine states of India.

The rising influence of China and India on the undergoing efforts to fight climate change is being increasingly scrutinized in international climate negotiations. With reason: latest available data suggest that China has already overtaken the United States in absolute energy consumption in 2009. Moreover India is projected to be the second-largest contributor to the increase in global energy demand to 2035. Although annual per capita energy demand in China and India remains far lower than in the OECD, relative success in tackling global warming will highly depend on current and future policy choices in these energy economies as well as United States [10]. 


\section{ENVIRONMENTAL AND ENERGY SUSTAINABILITY-A CHALLENGE FOR INDIA}

As India continues to develop, it has choices on how to accomplish its twin objectives of sustainable development and inclusive growth. India could choose to increase its focus on clean and effective technologies and practices to meet this difficult objectives (Mckinsey Report) [9]. By 2030, India is likely to have a GDP of USD 4 trillion and a population of 1.5 billion. This will swell demand for critical resources such as coal and oil with a parallel increase in greenhouse gas emissions (GHG). Considering that 80 percent of the India of 2030 is yet to be built, the country may have unique opportunity to pursue development while managing emissions growth, enhancing its energy security and creating a few world scale clean-technology industries. This would require that India leapfrog inefficient technologies, assets and practices and deploy ones that are more efficient and less energy - intensive. To achieve all this will be challenging, including funding an incremental investment amounting to 1.8 to 2.3 percent of GDP between 2010 and 2030 [9]. As regards to India, the question of sustainability is wide, clear and simple. Without a whole-hearted effort from the government and civil society, an imminent danger looms large over the country's horizon. Water crisis is a major impediment to the nation's growth. The action plans of the government towards clean rivers has propelled the country towards tangible reality. The burning question of groundwater arsenic pollution in eastern India has been answered as numerous projects of international footing uncovers the hidden solution. Water is intricately linked to the economic growth of the country. So this concerted effort towards sustainability in India.

\section{ISSUES IN SUSTAINABILITY RESEARCH AND ITS VISION}

In the beginning, one is mesmerized by the concept of sustainability. An obvious starting point for answering this question is with the term 'sustainability'. Although it remains a contested and mind boggling concept, since the 1980's there has been a noticeable shift in thinking from a primarily environmental conception of sustainability to a more tripartite prioritization of environmental, social and economic pillars of sustainability. This broader approach is embraced in the concept of sustainable development, which is commonly framed as the need for improving the quality of life all people now and into the long - term future. Work undertaken in the natural sciences, developing techniques to model and measure key aspects of environmental sustainability, remains an essential dimension of the sustainability research agenda $[7,10]$.

\section{VISION OF ENVIRONMENTAL SUSTAINABILITY}

Environmental sustainability remains a transformed vision striving towards a new future. Man's as well as scientist's vision is versatile, feasible yet unanswered. Research ground breaking and far-reaching needs a rigorous approach. Environmental sustainability along with stringent restrictions can bring a revolutionary change in future. Along with this concept, energy sustainability also can be focused towards a new futuristic vision. The world of scientific rigidity and scientific rigour can be a plausible solution $[7,10]$. 
Environmental sustainability is not a dream for the future but a plausible vision for the future. Water is a major component in the strive towards environmental sustainability. So environmental engineering and groundwater pollution reduction is the most important agenda in governmental regulations and restrictions. The vision of the environmental engineer and environmental scientist will be realized if the problem of water shortage and water contamination is successfully eradicated.

\section{VISION FOR TOMORROW}

The vision lying ahead is immense, wide and unmeasurable. Sustainability research will grow in years to come. Without sustainable development the world will not be able to stand. An irreversible sustainability growth pattern needs to be envisioned. The world and human society of tomorrow needs a viable and strong foundation of sustainability. The message of tomorrow is clear and simple- economic growth needs to go hand to hand with sustainability.

\section{CONCLUSION}

Environmental as well as energy sustainability have an intricate linkage. This treatise brings forward the visionary challenges the world will face in future. The success of the treatise is its determination towards sustainable future. The developing as well as developed society will be a forerunner to the immense challenges of future. The impending environmental challenges will witness a revolution if there is immense determination towards change on the part of all stakeholders of sustainability. Human society and mankind will have to gear towards a newer vision and newer focus to bring the immense changes in targeting a sustainable future. The question of energy and environmental sustainability is ever-growing and ground-breaking. Immense endeavour is required to achieve energy and environmental sustainability. In the developed and developing world, parameters needs to be adjusted according to needs and country-wise conditions. The truth and vision is emerging with successive years and successive generations. The world of tomorrow will be a better place to live if the answers to sustainability is transformed into reality.

\section{Acknowledgement}

The author wishes to thank the Management, Faculty and Staff of University of Petroleum and Energy Studies, Dehradun, India without whom this project would not have been accomplished.

\section{References}

[1] Robert Goodland, Annual Review of Ecology and Systematics 26 (1995) 1-24.

[2] Peter Newell, Jon Phillips, Dustin Mulvaney, Human Development Research Papers, Pursuing Clean Energy Equitably, United Nations Development Programme, November, 2011.

[3] Jeevan Nair, Impending global water crisis, Pentagon Press, New Delhi, India 2009, ISBN 978-81-8274-397-7. 
[4] A. N. Sarkar, Global climate change, Pentagon Press, New Delhi, India 2010, ISBN 978-81-8274-453-0.

[5] European Commission, Community Research, Renewable Energy Technologies, Long term in the $6^{\text {th }}$ framework programme, 2002/2006, http://ec.europe.eu/research/rtdinfo/

[6] Research and Development on Renewable Energies - A global report on photovoltaic and wind energy, International Science Panel on Renewable Energies, 2009, ISBN 978-0-930357-72-6.

[7] A. Franklin, P. Blyton, Researching Sustainability-A guide to social methods, practice and engagement, Earthscan Books 2011.

[8] Dilwyn Jenkins, Renewable Energy Systems-The Earthscan Expert Guide to Renewable Energy Technologies for Home and Business, Routledge - Taylor and Francis Group 2013.

[9] McKinsey \& Company, Report - Environmental and Energy Sustainability: An approach for India, Magnum Custom Publishing, New Delhi 2009.

[10] Sukanchan Palit, Environmental sustainability - a vision for the future, International Journal of Scientific and Engineering Research 4(2) (2013).

[11] Niko Roorda, Peter Blaze Corcoran, Joseph P. Weakland, Fundamentals of Sustainable Development, Routledge, Taylor and Francis Group 2012. 